Western University

Scholarship@Western

Aboriginal Policy Research Consortium International (APRCi)

2012

\title{
This is not a guide to Indigenous research partnerships
}

Karen Adams

Shannon Faulkhead

Follow this and additional works at: https://ir.lib.uwo.ca/aprci

Part of the Community-Based Research Commons

Citation of this paper:

Adams, Karen and Faulkhead, Shannon, "This is not a guide to Indigenous research partnerships" (2012). Aboriginal Policy Research Consortium International (APRCi). 164.

https://ir.lib.uwo.ca/aprci/164 
This article was downloaded by: [University of Western Ontario]

On: 18 November 2012, At: 07:48

Publisher: Routledge

Informa Ltd Registered in England and Wales Registered Number: 1072954

Registered office: Mortimer House, 37-41 Mortimer Street, London W1T 3J H, UK

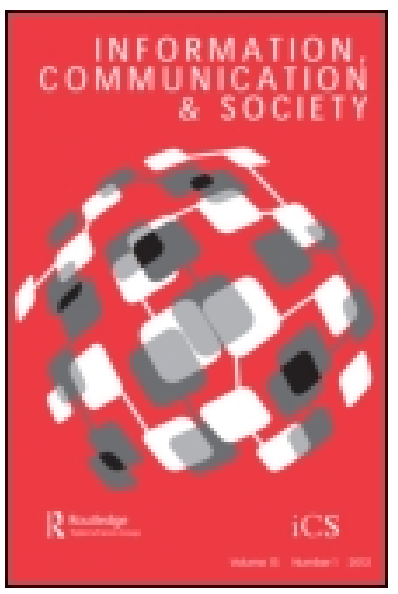

\title{
Information, Communication \& Society
}

Publication details, including instructions for authors and subscription information:

http:// www. tandfonline.com/loi/ rics20

\section{THIS IS NOT A GUIDE TO INDIGENOUS RESEARCH PARTNERSHIPS}

\author{
Karen Adams ${ }^{a} \&$ Shannon Faulkhead ${ }^{b}$ \\ ${ }^{a}$ Moondani Balluk Indigenous Academic Unit, Victoria \\ University, St Albans Campus VIC 8001, Australia E- \\ mail: \\ ${ }^{b}$ Monash Indigenous Centre, Monash University, VIC \\ 3800 , Australia \\ Version of record first published: 30 J ul 2012.
}

To cite this article: Karen Adams \& Shannon Faulkhead (2012): THIS IS NOT A GUIDE TO INDIGENOUS RESEARCH PARTNERSHIPS, Information, Communication \& Society, 15:7, 1016-1036

To link to this article: http:// dx. doi.org/ 10.1080/ 1369118X.2012.709260

\section{PLEASE SCROLL DOWN FOR ARTICLE}

Full terms and conditions of use: http://www.tandfonline.com/page/termsand-conditions

This article may be used for research, teaching, and private study purposes. Any substantial or systematic reproduction, redistribution, reselling, loan, sublicensing, systematic supply, or distribution in any form to anyone is expressly forbidden.

The publisher does not give any warranty express or implied or make any representation that the contents will be complete or accurate or up to date. The accuracy of any instructions, formulae, and drug doses should be independently verified with primary sources. The publisher shall not be liable for any loss, actions, claims, proceedings, demand, or costs or damages 
whatsoever or howsoever caused arising directly or indirectly in connection with or arising out of the use of this material. 


\title{
Karen Adams \& Shannon Faulkhead
}

\section{THIS IS NOT A GUIDE TO INDIGENOUS RESEARCH PARTNERSHIPS \\ But it could help}

\begin{abstract}
Development of research partnerships can cause confusion, as there is not and cannot be a step-by-step guidebook to community partnerships. Each one is different because each partnership is unique. The aim of this article is to unpack some of the workings of Indigenous research partnerships. In this article we use a mini-literature review of Australian research, and methods of self-reflection and 'Yarning' to draw on our research partnership experiences of having been community partners to researchers, as researchers ourselves partnering with community, and Indigenous knowledge shared with us through collaborative research, and community relationships. The literature review is a tool to show the tendency for research partnership methods to be viewed as hierarchical and/or lateral based on the descriptions within the literature, and illustrate some of the issues experienced from an Indigenous perspective when operating within a Western paradigm. Although research partnerships can be complex, the rewards of the collaboration are many, including benefits for all partners and research outcomes that can be adopted at the community level. Emerging issues include partnership methodologies, evaluation and quality assurance.
\end{abstract}

Keywords research partnership; Indigenous; participation; communication; quality; evaluation

(Received 9 August 2011; final version received 30 June 2012)

\section{Introduction}

In various Indigenous research forums we have heard iterations on the phrase that 'there is what you need to do to meet ethics approval, and then, there is how you work with community'. This reinforces division between community processes and academic methodologies, methods, ethics, permissions and ways of representing and presenting results. These types of statements and other ominous references result in some academics regarding community partnership 
research with trepidation. Researchers and community participants can encounter confusion, misunderstandings about methodology, assumptions about the research processes and/or defeatism at the prospect of undertaking what is perceived to be a complex and time consuming activity (Israel et al. 1998). We do not deny that community research partnerships are messy, complex and time consuming, but this experience can also make the research fun and beneficial on so many levels. One of the reasons for the perception of messiness is because there is not and cannot be a step-by-step guidebook to community partnerships. Each one is different because each partnership is different. For research and community partnerships to succeed, confusion needs to be reflected on, and worked through, and the messiness understood. These processes improve the research outcomes and increase the success of their adoption and use at the community level (Minkler 2005). Whilst there is a good deal of advice available about 'what' researchers should do when working with Aboriginal and Torres Strait Islander peoples (e.g. Australian Institute of Aboriginal and Torres Strait Islander Studies 2000; VicHealth Koori Health Research and Community Development Unit 2000; National Health and Medical Research Council 2006), little has been written about 'how' researchers can achieve this in a practical 'hands-on' way. This article intends to reflect upon and discuss literature on projects self-identified as community partnerships, whilst drawing upon our self-reflection in this field through the Indigenous research method known as 'Yarning'. There are varying explanations of partnerships. For the purposes of this article a partnership is defined as two or more entities taking part in an undertaking with shared risks and benefits (Oxford University 2012).

\section{Background}

Indigenous peoples of Australia have been conducting various forms of research for generations. For instance, they have been engaging in intergenerational knowledge sharing and documenting activities relating to seasons, historical events, such as the ice age, and medicinal practices using oral cultural research approaches (McCarthy et al. 1997; Grieves 2002). The onset of colonization disrupted these practices and Indigenous peoples have adapted to new ways of conducting research. This has included changing the colonizer/Western paradigm of being researched to becoming researchers, partners in research or conducting new ways of research. In fairly recent years in Australia, various reports have recommended that Indigenous peoples should have more self-determination in research (Commonwealth Government 1987). Debates have also occurred about Indigenous peoples' involvement in research (Moreton-Robinson 2003) which have undoubtedly influenced the development of Indigenous research ethics guidelines which are highly relevant to research partnerships (Australian 
Institute of Aboriginal and Torres Strait Islander Studies 2000; National Health and Medical Research Council 2003a).

We, as authors of this article, have had various experiences in partnership research, located predominantly in south-eastern Australia. Karen Adams has worked in and with Aboriginal Community Controlled Health Organizations over a period of 20 years. This has involved working in community organizations with researchers and working as a researcher with community organizations, conducting research in areas such as social network analysis, child health, peer mentoring, health programme evaluation and analysis of surveillance systems (Adams \& Spratling 2000, 2001; Adams 2006; Adams \& Walker 2006; Adams et al. 2004a, 2004b, 2006a, 2006b, 2012; Paasse \& Adams 2011).

Shannon Faulkhead has worked for nine years with the Koorie Heritage Trust Inc. (an Aboriginal cultural centre) and eight years as an academic researcher working in the field of Archives and Indigenous Studies on projects partnered with Aboriginal communities and community organizations, including the 'Trust and technology: Building an archival system for Indigenous oral memory' project (T\&T Project) (http://www.infotech.monash.edu.au/ research/centres/cosi/projects/trust/), PhD research 'Narratives of Koorie Victoria' (Faulkhead 2008, 2009), and 'Holding Gunditjmara knowledge: Records and people working together'. We draw on this experience and the review of relevant literature to discuss research partnerships with Indigenous peoples.

\section{Methods}

The aim of this article is to investigate research partnership with Indigenous peoples. We use two methods to achieve this aim: a mini-literature review to develop an understanding of how others self-define partnership research when working with Indigenous communities; and Collaborative Yarning to draw on our personal experiences and Indigenous knowledge pertaining to partnership research in order to analyse and critique the literature.

\section{Mini-literature review}

The purpose of the mini-literature review is to provide a sample of partnership research with Indigenous peoples as reported in published research articles. It does not aim to be comprehensive, but rather to allow the authors to draw on self-definitions of Indigenous partnership research to illustrate the broad use of this term within the social sciences and health fields, and the differences from and similarities with our personal experiences working with Indigenous Australians (see Collaborative Yarning below). The inclusion criteria for the mini-review were published journal articles describing Indigenous research 
partnerships in Australia. Personal opinion on research partnerships was excluded to ensure a focus on practical and real case study experiences. Notably some of the articles we reviewed did not describe the research partnership but rather focused on research results. We ended up excluding these articles as we were unable to discern the partnership processes used. Literature for review was sourced from 2000 to 2010. This time frame was selected as the literature was considered of relevance to current socio-political environs. We identified search terms that related to Indigenous and partnership research based on our personal research experiences. Indigenous search terms included: Indigenous, Aboriginal, Torres Strait Islander, and First Nations. Additional search terms paired with those above were research or evaluation and partnership, collaboration, team, engagement, relationship, and alliance or group. These search terms were used to extract articles from the following databases: Proquest, SAGE Premier, Science Direct, Informit, Jstor and SSRN. These databases were chosen as their size is inclusive of a variety of place and disciplines. In all, 20 articles were retrieved: one from New Zealand and Australia, and 19 from Australia. Articles were predominantly from the social sciences (8) and health (12) fields, although many of them also included references to cultural heritage and knowledge.

\section{Collaborative Yarning}

Yarning is a recognized narrative research method that involves self-reflection and deep discussion about a particular issue. For this article we specifically utilized Collaborative Yarning which involves exploring similar or different ideas in explaining concepts, leading to new information and understandings (Bessarab \& Ng'andu 2010). The reason we selected this method to reflect upon the miniliterature review was to allow us to draw upon self-reflection of our personal research experiences as well as those described to us anecdotally by Indigenous people. Russell (2005) has referenced the following definition of Indigenous knowledge by D.M. Warren as one that is 'adopted largely by the United Nations and UNESCO’ (p. 170):

Indigenous knowledge (IK) is the local knowledge - knowledge that is unique to a given culture or society. IK contrasts with the international knowledge system generated by universities, research institutions and private firms. It is the basis for local-level decision making in agriculture, health care, food preparation, education, natural-resource management, and a host of other activities in rural communities.

(Warren in Russell 2005, p. 170)

Throughout our lives knowledge on research and Indigenous communities has been shared with us. Very little of this knowledge has been referenced in 
written form, with much of it building upon itself within an oral space that is difficult, if not at times, impossible to reference within Western academic strictures. Despite its oral form, this is important Indigenous knowledge that has directed our thoughts, methods and ways in which we engage in partnership research. This knowledge and our experiences are what are referenced through Yarning in this article.

Together we reviewed the literature and utilized the above inclusion and exclusion criteria to select final papers for review. We then read these papers together, identified the partnership processes described, and recorded these into a matrix (see Table 1). This matrix became the focus of further Collaborative Yarning about the potential strengths and weaknesses of using various partnership processes based on our experience of working in and observing other partnership research. The Yarning identified themes for grouping similar processes together. We also drew on information provided in the papers that described process strengths and weaknesses. We recorded this Yarning into a written format that is described below.

\section{Potential bias}

As with all research, methods used in this research contain potential bias. As this article focuses in part on the authors discussing issues they have experienced in both academic writing and Indigenous communities, it is impossible for bias not to occur as the discussion is based upon experiential knowledge filtered through the methods of self-reflection and Collaborative Yarning. We acknowledge that the discussion could read as if we assume that all Indigenous Australians, and academic disciplines should take similar approaches to how partnership research should be conducted, and therefore should undertake the same methods. That is not our intention. The article aims to illustrate that difference is better than 'okay', and that various methods of partnership research can be employed dependent on the research and peoples involved.

With reference to the mini-literature review, the relatively small number and type of articles may introduce potential biases. For example, there may be further partnership processes described in grey literature. The types of search terms may have introduced bias as the authors are only familiar with those used in social sciences and health. The databases used and limitation to articles in English may also be issues that might also result in gaps in the mini-literature review in some discipline areas.

\section{Discussion}

The two main partnership processes we identified were lateral and hierarchical (see Table 1). A hierarchy is 'an arrangement or classification of things according 
THIS IS NOT A GUIDE TO INDIGENOUS RESEARCH 1021

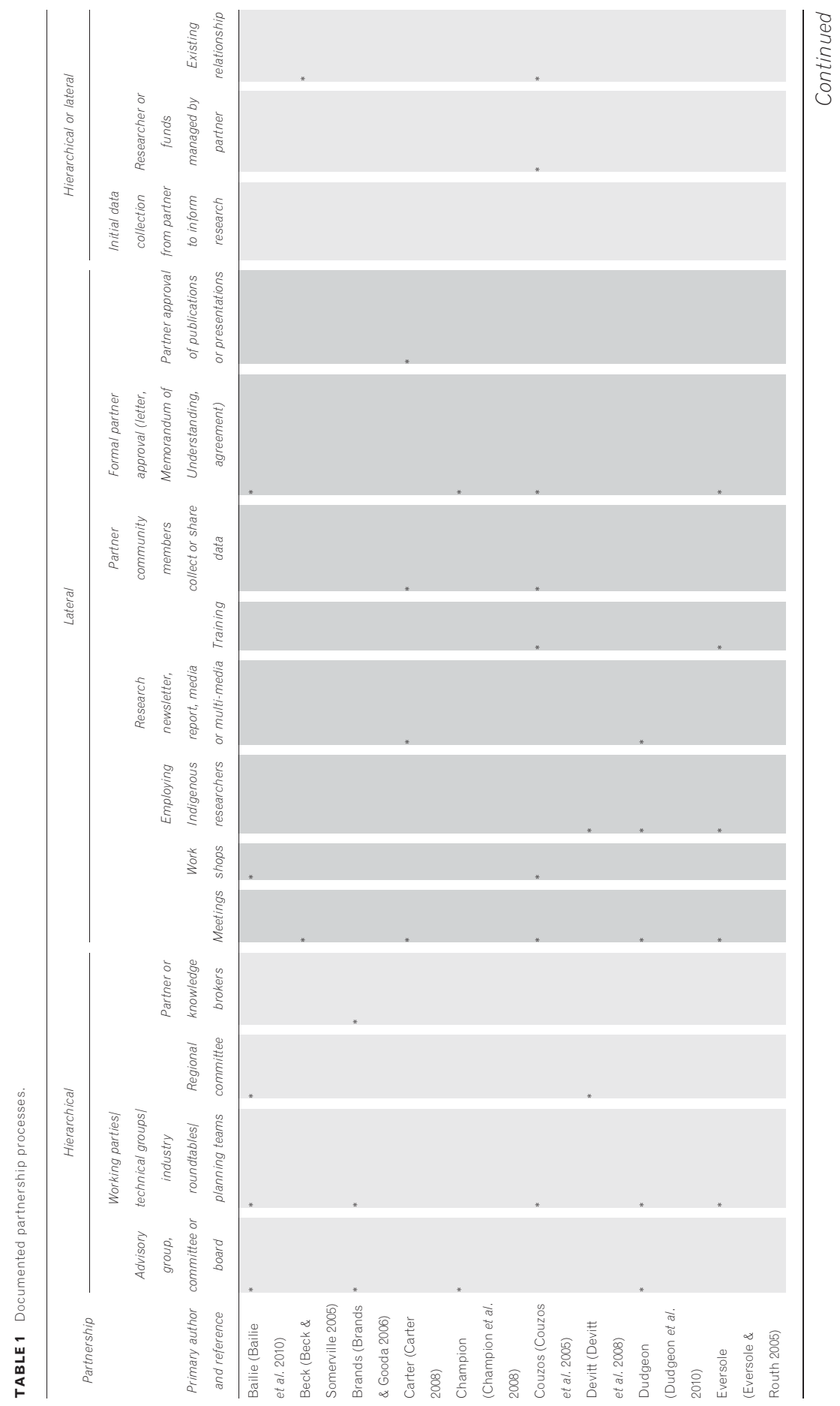


1022 INFORMATION, COMMUNICATION \& SOCIETY

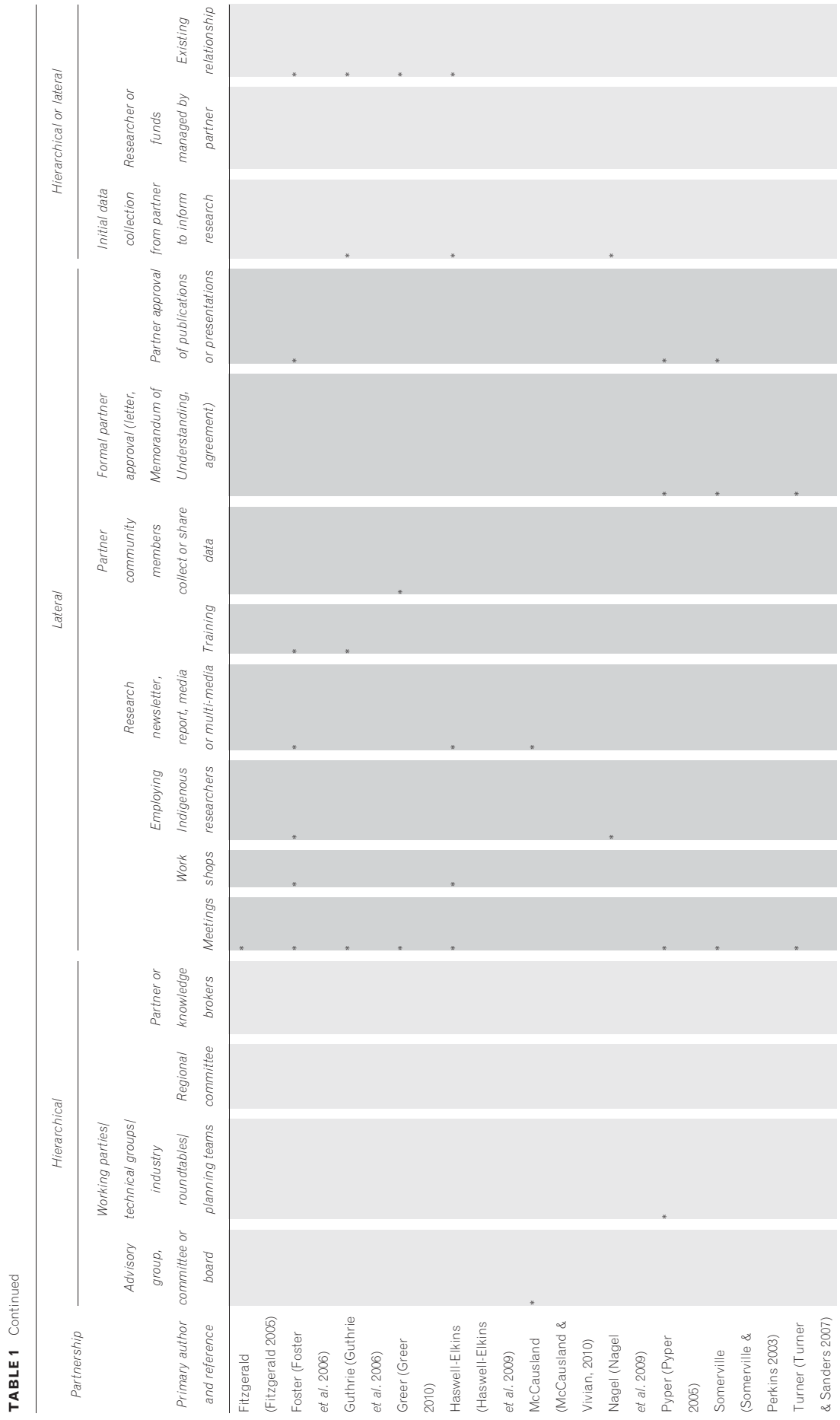


to relative importance or inclusiveness', while laterality is 'a side part of something' (Oxford University 2012). In addition, several other groupings emerged including partnership time, power balancing and evaluation. This analysis criterion is not about whether hierarchical partnerships are better or worse than lateral partnerships, but provides a tool to see how various partnerships can operate.

\section{Hierarchical partnership processes}

The literature described a number of hierarchical partnership processes including advisory groups, working parties, technical groups, regional groups and partnership brokers (see Table 1). A risk with hierarchal research partnership processes is they have potential to disenfranchize research participants by excluding them from input opportunities into all stages of the research processes. Research findings inevitably impact on participants so their involvement in research processes can strengthen research in a number of ways. It can improve acceptance and implementation of research findings, and provide insider knowledge that can direct the research to collect and interpret more meaningful and more balanced (less biased) data. For research teams developing hierarchal partnership models, it is important to consider whom the partners are and how their participation will be included in all research stages, beginning with the research question. Research participation assessment tools exist and can be a useful way to assure quality of partner engagement (Mercer et al. 2008).

The literature described varying degrees of partner participation on advisory groups. For instance, representation might be through the inclusion of Indigenous experts or Indigenous researchers (McCausland \& Vivian 2010). These people, if providing intellectual property, are co-investigators and usually do not represent the target research partner. Other studies had attempted to increase laterality of advisory groups by providing open attendance or inviting people from the target 'study group' or partnership group (Haswell-Elkins et al. 2009). An important consideration for advisory group make-up was inclusion of stakeholder partners who can potentially ensure that research findings change policy or practice (Foster et al. 2006). These stakeholders could be research participants, organizations, practitioners, and/or policy makers dependent upon the research aims and anticipated research outcomes.

The literature revealed that further hierarchy tiers had been added in some cases below advisory groups, such as, working parties, regional committees, industry roundtables or technical groups. In some cases two committees sat in this tier, for instance, a technical advisory and separate community advisory groups (Weston et al. 2009). This division assumes that community and technical advice are disparate, whereas we would argue they are inevitably linked. Our Yarning identified that these processes and/or structures also have potential to reduce transparency about the research process; contrary to ethics guidelines 
whereby Indigenous people should be involved in all stages of research (National Health and Medical Research Council 2003a). Multiple research advisory groups can be resource intensive and, in our experience, sometimes two groups morph into one advisory group or one group is deemed more practicable. If communities are working with a number of researchers, the researchers may not wish to share information because they fear loss of intellectual property due to their knowledge being shared with others prior to publication. Ideally concerns about use of intellectual property should be transparently discussed and resolved prior to the research taking place.

Another hierarchical tier identified in the literature comprises partnership or knowledge brokers (Brands \& Gooda 2006). The broker's role is defined as involving the development of the research partnership with Indigenous communities and the formation of groupings of Indigenous experts on a particular theme to assist in facilitating the research. Why it is necessary to differentiate this kind of role from that of a research investigator is intriguing. Just as there are epidemiology, anthropology or sociology researchers, there are partnership researchers. Calling an Indigenous research partner who plays the brokerage role a broker rather than a researcher diminishes their role and fails to acknowledge their expertise as a researcher. It can lead to brokers being treated as liaison officers with little say in research processes, although they largely carry the responsibility for the accountability of the research to community partners as they are the 'face' of the research team. In terms of networks between researchers and partners, if the broker link is removed (i.e. the broker leaves the project) the research is at risk of stalling.

Advisory committees or group meetings can be vital to a partnership allowing partners to share information, seek advice and make decisions together. Establishing the purpose of the group early can increase participation and transparency of research. It is advantageous for partners to plan group process options, such as, meeting structure, time, location and methods of communication. For example, communication can happen in many formats, regular meetings, Skype, teleconferences or written updates with a small number of face-toface meetings. Facilitation of these groups ideally aims to involve all partners. Tokenistic advisory committees created simply to meet funding or ethics criteria can create patronizing and frustrating experiences. If researchers fear community partner input and feel a need to control advisory groups, it indicates a poor partnership with little trust. This kind of dysfunction can lead to problems and frustrations such as those described in the quote below:

The committee was established to provide feedback, advice and discussion throughout T\&T whilst meeting as a group twice a year. It soon became apparent that the Advisory Committee was not working effectively as indicated by lack of interest by some members, complaints regarding the lack of discussion, and withdrawal from the project by a Koorie Elder. The 
breakdown of the Advisory Committee could be linked to a number of things including confusion of purpose, infrequency of meetings, and lack of communication. It was felt that the meetings had become project team information sessions, instead of occasions for the Advisory Committee to provide advice.

(Faulkhead et al. 2007, pp. 50-51)

Benefits of advisory groups can be multiple particularly as trust grows (Adams \& Spratling 2001). Our Yarning identified that healthy and functional partnerships tend to be more flexible and solution-orientated where problems are discussed and addressed openly. Unhealthy partnerships tend to be stressful and anxious with poor communication leading to a shift of focus to what each partner is 'up to' or suspicion about motive rather than on completing the project in the most productive way. This often translates into meetings upon meetings about how something should be done rather than doing it, or the project stalling with difficulties experienced in progressing partnership communication.

Our Yarning also explored how project-specific advisory committees are sometimes simply not feasible. For instance, there may be inadequate resources for an advisory committee to exist, such as, limited personnel time or costs of travel. Once the research plan is established, members may be happy to receive updates on progress. In other cases the research project may involve close day-to-day dealings between community and researchers that essentially negate the need for an advisory committee. These types of arrangements lend themselves to lateral partnership methods.

\section{Lateral partnership processes}

Lateral partnership processes described in the literature (see Table 1) include meetings, workshops, employing Indigenous community members in the project, newsletters and media to inform partners, training for partners, formal partner agreements, partner approval of public documents and involving Indigenous people in data collection. These types of processes can transparently clarify research development and progression, requiring partners to meaningfully participate and engage in the research side by side. Like hierarchical processes, lateral processes are linked to the quality of partner communication and participation.

Meetings were the most common lateral activity described in the literature (see Table 1). In our experience, meetings, workshops and conversations work best when there is a (culturally) safe space. This requires consideration of communication and physical space. Some projects described meeting on the partner's traditional country as significant in allowing the research team to engage with the lands of traditional custodian partners (Beck \& Somerville 2005; Pyper 2005). 
Our Yarning acknowledged that a meeting on community ground has benefits for researchers. For instance, it can provide further partner understanding, allow networking and participation in cultural events. For Indigenous researchers it can be identity affirming and provide avenues for new and renewed connections. Some projects involve large geographic spaces, so rotating meetings around the locations and identifying the most accessible community spaces are possibilities. Meetings in community partner spaces can increase comfort for everyone and enable them to speak with authority. In urban areas where people are more likely to have moved to another traditional custodian's land, Indigenous organizations are possible meeting places. Whilst there is evidence that academia is evolving towards an acceptance of the importance of the wider community in research processes, universities can still be viewed by Indigenous peoples as a colonial presence (Tuhiwai Smith 1999). This plus the sheer size, travel time involved in visiting and unfamiliarity of some universities mean that meeting at them may become a barrier. That said, there are occasions when Indigenous partners prefer to meet at universities or other partner venues; they may be interested to find out more about the partner or prefer to be away from the distractions of their day-to-day work.

Literature also described varying types of communication. Consultation was one method referred to (Turner \& Sanders 2007; McCausland \& Vivian 2010). To consult is defined as 'to refer to for information' (Oxford University 2012), a one-way communication pathway whereby information is obtained from the community partner to develop research. In the opposite direction the term research transfer or translation has been used (Watson et al. 2002; Brands \& Gooda 2006; Bailie et al. 2008; Dudgeon et al. 2010). Transfer means to move from one place to another and translation the process of moving something from one place to another (Oxford University 2012), inferring researchers are moving findings to others in a single direction. In a partnership, decisions are made based on information, discussion and thoughts provided by all partners. Partnership research requires researchers to have flexibility and have confidence in their communication skills. Partner negotiations discuss risks and benefits, and should occur in a space where all partners can speak with authority about their needs. This can mean listening to criticism and voicing confusion to enable further investigation or understanding (Beck \& Somerville 2005). Anxiety or defensiveness about criticism can prevent flexibility and responsiveness that will enable solutions to problems that may arise. Partners have their own plans and priorities and sometimes they fit with the aims of proposed research projects and sometimes they do not. It is possible that proposed research can be tweaked and altered to fit community needs and in the process create benefit to the research project as well (Faulkhead 2008). In fact obstacles and contradictions can be important junctures that provide productive analytic information to improve research quality (Beck \& Somerville 2005). These occurrences can unearth episodes where evidence and research methods from 
colonizing views are a misfit when applied to Indigenous contexts (Tuhiwai Smith 1999). Our Yarning identified that acknowledging a project is not progressing in a timely fashion and addressing ensuing issues will often save valuable time and improve the partnership. Each project will develop its own challenges that need to be acknowledged and worked through for the research to be successful for all partners.

Lateral partnership approaches also offer reciprocity for partners. Reciprocity can be expressed in many ways with research participants and community partners. It assists in developing trust and respect within partnerships. The literature described several lateral reciprocity activities including employment of Indigenous people with research funds, partner training, acknowledging partners in public documents and research that provides tangible partner benefits (see Table 1). Once again these processes can vary in quality.

Employing Indigenous people in research projects was a frequently mentioned method of reciprocity. Our Yarning acknowledged this can provide benefit in many ways, particularly as it highlights to Indigenous community partners that Indigenous involvement is important. However, employment of Indigenous people by institutions to facilitate research that is unwanted or not a priority for Indigenous partners indicates poor quality and patronizing behaviour. It is also important that Indigenous researchers are recognized as such. One project described use of a peer interviewer (Devitt et al. 2008) inferring that Indigenous people who conduct interviews are different to researchers. We suggest that attempts to re-label people as peers, liaisons or engagement officers can diminish their role considerably at the expense of the benefit to the research team that stems from respecting and acknowledging their role as members of the team.

Training was also mentioned as a reciprocity activity. Training in cultural awareness had been provided for non-Indigenous researchers (Somerville \& Perkins 2003) to address cultural confusion experiences in research. Common expressions of confusion include: guilt such as believing that an Indigenous person should have their job; misplaced responsibility believing they are directly responsible for atrocities in the past; feeling inadequate or ill-equipped to work with another culture; frustration at not understanding why people act in a certain way; and cultural blindness or an unawareness of cultural practices (Merriam et al. 2001; Adamson \& Donovan 2002). Our Yarning found that cultural confusion can become normalized and accepted behaviour by both Indigenous and non-Indigenous people. In order not to burden community partners, researchers can resolve cultural confusion through professional development such as via relationships or counselling external to the partnership.

Difficulties and self-doubt are not the sole provenance of the non-Indigenous researcher. It has been asserted that research is adequate or improved if conducted by Indigenous people (Onemda Vichealth Koori Health Unit 2008). However, Indigeneity does not equate to a good partner researcher. 
Guidelines for supporting Indigenous researchers suggest that assumptions of existing partnership skills are risky and unreasonable, and that a rite of passage or trust building process between the researcher and the community is required for beneficial research to occur (Laycock et al. 2009). Our Yarning argued that rite of passage is an inadequate and mystified term. Partnership research skills require professional development just as other research skills do. Indigenous people, and indeed others, entering this realm need guidance and support. This support can include advising about: people to talk to; phrasing emails and correspondence; building informal or formal networks of support; flexibility; appropriate activities to be doing in community and researcher spaces; and developing understanding about time poor community environments. In reality this requires training or a mentor with previous expertise in this area. Mentors are not only senior academics but also people such as Elders, Indigenous administrative staff or managers in community organizations. Some Indigenous researchers will have developed skills and knowledge about working in healthy partnership environments through study and previous work experience. Others may have limited experience or worked in environments where unhealthy partnership processes have been modelled. There will also be Indigenous researchers who have no interest or desire to undertake partnership research.

The literature also described training in research skills for Indigenous community partners (Guthrie et al. 2006). Our Yarning found that an important consideration when planning this type of training is assessment of the research relevance to the organization's or individual's core business. Time availability is another consideration.

\section{Hierarchal or lateral processes}

Our Yarning identified there was literature describing three processes that could be classified as hierarchical or lateral methods depending on how they are implemented (see Table 1). For instance, initial data collection from participants had been collated to inform research progression. This could then be used laterally by partners to plan next steps together, or hierarchically by researchers to plan research projects without involving partner discussion. Hierarchal or lateral processes could also apply if research funds were managed by Indigenous partners. Use of existing relationships could be lateral, such as research extending from a previous successful partnership. It can also be hierarchical, for instance, if the research was tied to a funding agreement or another relationship such as receiving university funds for programmes. It is important to declare and acknowledge existing and previous relationships and/or partnerships. By recognizing this, potential conflicts of interests or power imbalances can be prevented. Lack of transparency can 
create fear of reprisal or harbour resentment leading to further suspicion and negative attitudes toward research partnerships.

\section{Balancing partner responsibility}

Our Yarning about the literature identified research processes and methods focusing on balancing partner responsibility. Training for all partners was one process used ensuring an increase in skill base for everyone (Guthrie et al. 2006). The importance of all partners providing research agenda transparency has also been identified (Somerville \& Perkins 2003). Similarly, our Yarning supported a need for all partners to declare early: who we are, who we represent, what we hope to gain from the research and what benefits the research brings and for whom. Partners can then make an informed choice whether or not it is valuable to pursue a research project and if mutual benefit will be gained as impetus for the partnership to exist (Boser 2006). In contrast, research guidelines often focus on the community partner benefit (National Health and Medical Research Council 2003b). This is important to consider particularly as research organizations are often in a strong position of power; however, Indigenous community organizations also initiate research partnerships with the understanding that research organizations will jointly benefit (Couzos et al. 2005; Foster et al. 2006). As community representatives we have experienced some non-transparency with research agendas. Occasionally researchers (Indigenous and non-Indigenous) will not accept a partnership refusal and non-transparently embark on support-shopping with potential partner organization workers or board members to progress their research agenda. Another tactic is to disguise a research advisory group as a think-tank, a round table or a forum in order to involve partners. We have also known researchers to allude to a partnership in order to gain research funding, without declaring the funding application to the partner organization. These non-transparent processes waste resources, create distrust and undermine partners.

Our Yarning also noted the complex process of colonization, involving both external and internalized oppression, can affect the responsibility balance in a partnership, particularly in terms of participation. Common forms of colonial oppression include physical violence, psychological violence, identity denial and diminishing, denial and questioning of knowledge and intelligence, patronizing behaviour, questioning of ability to parent, a belief of sub-normal intelligence, exotic objectification and more (Tuhiwai Smith 1999). Internalized oppression is when messages received from oppressors are internalized by the oppressed and then applied to themselves and people like themselves, particularly to those who step outside stereotypes of the group or community to which they belong (McBride 2003). For instance, one paper described peer judgement as a barrier to Indigenous people participating in policing (Eversole \& Routh 2005). Our Yarning identified that research investigators and participants 
attempting to address internalized oppression can come under criticism as it challenges self-perception. In our experience legitimate criticism will tend to be nonpersonalized, well informed and transparent. Mindfulness of occurrences of these forms of oppression and clear processes for addressing criticism can save stress and time.

External oppression is a continued expression of colonization (McBride 2003). An example of this in the literature was reference to time as a barrier and difficulty when working with Indigenous partners (Turner \& Sanders 2007). While in contrast Carter (2008) simply noted that time was a necessary component to the quality of the research. Analysis of research difficulty requires consciousness of exhibiting idealistic or inflexible practices where partners are viewed in terms of Other and not fitting the researcher's philosophy (Cousins \& Simon 1996). Our Yarning found that often researcher priorities of acquitting budgets, final reports, publication output and funding applications are at odds with partner priorities and timeframes. This can lead to anxiety and frustration for partners, particularly those involved in developing new partnerships that take more time. Involving research funders in advisory committees can alleviate some of this stress as they are exposed to and included in the day-to-day realities of time required to engage in partnership research. In Yarning about time issues we identified that Indigenous organizations are often time poor in regard to research as they are constructed to achieve specific aims, such as delivery of services or material production. Often research is not the primary goal or concern, with the majority of time and resources mobilized at achieving organization aims. Due to the need for staff to respond rapidly to priorities in organizations, even when staff are genuinely committed to research they may be unable to be available at times ideally required. For researchers this may mean altering methods and research styles to find creative solutions for time poor environments. Individuals representing communities can also change during a project for a number of reasons, such as, illness, death, burn out, family responsibilities and changes to the governance or administration of organizations. These situations require flexibility and responsiveness from the researcher, as they need to re-negotiate and build relationships with these new partner representatives. Transparent documents and agreements can assist in this process as they provide a clear history of the project to date and any misinterpretations or questions can be quickly addressed by referring to the documents.

Research methods have also been used to balance responsibilities. One project explored the discourse on oppressed and oppressors to strengthen participant partnerships (Eversole \& Routh 2005). This effectively shifted the focus from Indigenous people being the problem to a partnership responsibility to resolve problems (Eversole \& Routh 2005). Other methods involve recognizing and integrating Indigenous and non-Indigenous knowledge or two way learning (Beck \& Somerville 2005; Pyper; 2005; Carter 2008; Haswell-Elkins et al. 
2009). These methods use non-Indigenous research knowledge and resources alongside Indigenous knowledge and resources to gain understanding about a situation or find a better way to implement an activity.

\section{Partnership evaluation}

The literature described a number of research partnerships operating under the assumption that their existence inferred quality and success. While this may be true, in fact only four studies had evaluated the research partnership. One study had evaluated partner participation level using quality and validity measures. Quality of participation was measured by the number of participants involved in partner negotiations and their gender, age, culture and socioeconomic diversity. This study found that utilizing a social capital framework (Woolcock 1998) was useful to evaluate participation and identify participation successes and gaps. A second study had used evidence and guidelines on research collaboration to design and implement a project. Data on collaborations, conversations and intersections were then collated using participant observation methods. The findings of this project identified reflective cycles (rather than a pre-designed linear approach) to engage partners in decision making (Carter 2008). A further study used the concept of the contact zone as a method of understanding intercultural work (Somerville \& Perkins 2003). While this theoretical perspective provides a lens to view partnerships, it did not appear to be a systematic way to provide evaluation. The fourth evaluation used qualitative interviews to describe outcomes and changes that had occurred with participants engaged in the research (Eversole \& Routh 2005). Research partnerships are diverse (as outlined in Table 1) and evaluation processes ideally would include measurement of hierarchical, lateral and power balancing components.

\section{Conclusions}

There are many aspects to partnership research that can result in success and failure - often dependent on many factors. Unfortunately this article is unable to address them all. As such, this article is not a guide to conducting partnership research but an exploration of how each research partnership is unique with its own processes and solutions to issues that inevitably emerge as the partnership develops. Essentially it is up to the partners to jointly decide which processes work best for their own circumstances. Partners can draw on hierarchical, lateral and balancing responsibility processes to develop research projects and these can vary in quality. Partners can benefit by having access to new information and networks that each partner is privileged to know about. They can also develop further skills and confidence in partnership processes and understand more about each other's organizations. These approaches may also lead to further projects that benefit each group and provide further solutions and 
resources. Partnership methodologies, evaluation methods and quality assurance processes are emerging in the field of partnership research.

Ethics guidelines have been developed, the number of Indigenous researchers is increasing, as are culturally sensitive non-Indigenous researchers, and communities are becoming more research savvy. We conclude that there is more to working in partnership with Indigenous communities than just meeting ethics guidelines. Working in community research partnerships requires both community and researchers taking responsibility in research in open and transparent ways. It requires careful thought about how to engage communities in research to support their aims and also create benefit for researchers. In addition, consideration needs to be given to realistic time and resource requirements.

This article has also provided the authors with an opportunity to explore how others describe their research within written articles. It is interesting to note that, overall, the mini-literature review has shown that often the articles resort to a Western paradigm in the way in which they write about their research. Unfortunately we (the authors) currently do not have an understanding as to 'why?'. Is it due to a desire to work within comfort zones, the requirements of journals, word limits or other reasons? We also found Yarning an interesting and useful process when reflecting in a holistic way on other's work, our experiences and the insights contained in Indigenous knowledge. As a new process for us, we are unsure of its potential in our fields of research, but it is a process which we hope to draw on and develop further in the future.

\section{References}

Adams, K. (2006) Koorie Kids and Otitis Media, University of Melbourne, Parkville. Adams, K. \& Spratling, M. (2000) 'Supporting Koori health workers', Australian Nursing Journal, vol. 7, no. 7, p. 3.

Adams, K. \& Spratling, M. (2001) 'Keepin Ya mob healthy: aboriginal community participation and aboriginal health worker training in Victoria', Australian Journal of Primary Health, vol. 7, no. 1, pp. 116-119.

Adams, K. \& Walker, H. (2006) 'Aboriginal health worker training and smokes', Aboriginal Health Worker Journal, vol. 30, no. 2, pp. 15-16.

Adams, K., Dixon, T. \& Guthrie, J. (2004a) 'Evaluation of the indigenous hearing health program at the Ramahyuck aboriginal cooperative', Australian Journal of Health Promotion, vol. 15, no. 3, pp. 205-210.

Adams, K., Kavanagh, A. \& Guthrie, J. (2004b) “"Are you aboriginal and/or Torres Strait Islander?”: improving data collection at BreastScreen Victoria', Australian and New Zealand Journal of Public Health, vol. 28 (April), no. 2, pp. $124-127$. 
Adams, K., Nickson, C. \& Saunders, M. (2006a) 'Indigenous health: is it every researchers' responsibility?' Australasian Epidemiologist, vol. 13 (May), p. 1.

Adams, K., Rumbiolo, D. \& Charles, S. (2006b) 'Evaluation of the "No more Dhonga" smoking cessation short course at Rumbalara', Aboriginal Health Worker Journal, vol. 30, no. 5, pp. 11-12.

Adams, K., Burns, C., Liebzeit, A., Ryschka, J., Thorpe, S. \& Browne, J. (2012) 'Use of participatory research and photo-voice to support urban Aboriginal healthy eating', Health \& Social Care in the Community, Article first published online: 5 March 2012, DOI: 10.1111/j.1365-2524.2011.01056.x.

Adamson, J. \& Donovan, J. L. (2002) 'Research in black and white', Qualitative Health Research, vol. 12, no. 6, pp. 816-825.

Australian Institute of Aboriginal and Torres Strait Islander Studies (2000) Guidelines for ethical research in Indigenous studies, Australian Institute of Aboriginal and Torres Strait Islander Studies, Canberra.

Bailie, R., Si, D., Connors, C., Weeramanthri, T., Clark, L., Dowden, M., O'donohue, L., Condon, J., Thompson, S., Clelland, N., Nagel, T., Gardner, K. \& Brown, A. (2008) 'Study protocol: audit and best practice for chronic disease extension (ABCDE) project', BMC Health Serv Res, vol. 8 , pp. 184.

Bailie, R., Si, D., Shannon, C., Semmens, J., Rowley, K., Scrimgeour, D., Nagel, T., Anderson, I., Connors, C., Weeramanthri, T., Thompson, S., Mcdermott, R., Burke, H., Moore, E., Leon, D., Weston, R., Grogan, H., Stanley, A. \& Gardner, K. (2010) 'Study protocol: national research partnership to improve primary health care performance and outcomes for Indigenous peoples', BMC Health Services Research, vol. 10, p. 129.

Beck, W. \& Somerville, M. (2005) 'Conversations between disciplines: historical archaeology and oral history at Yarrawarra', World Archaeology, vol. 37, no. 3, pp. $468-483$.

Bessarab, D. \& Ng'andu, B. (2010) 'Yarning as a legitimate method in indigenous research', International Journal of Critical Indigenous Studies, vol. 3, no. 1, pp. 37-49.

Boser, S. (2006) 'Ethics and power in community-campus partnerships for research', Action Research, vol. 4, no. 1, pp. 9-21.

Brands, J. \& Gooda, M. (2006) 'Putting the users of research in the driver's seat: the cooperative research centre for aboriginal health's new approach to research development', Australian Aboriginal Studies, no. 2, pp. 27-35.

Carter, J. L. (2008) 'Thinking outside the framework: equitable research partnerships for environmental research in Australia', Geographical Journal, vol. 174, no. 1, pp. 63-75.

Champion, S., Franks, C. \& Taylor, J. (2008) 'Increasing community participation in an aboriginal health service', Australian Journal of Rural Health, vol. 16, no. 5, pp. 297-301.

Commonwealth Government (1987) Royal Commission into Aboriginal Deaths in Custody, Commonwealth Goverment, Canberra. 
Cousins, J. B. \& Simon, M. (1996) 'The nature and impact of policy-induced partnerships between research and practice communities', Educational Evaluation and Policy Analysis, vol. 18, no. 3, pp. 199-218.

Couzos, S., Lea, T., Murray, R. \& Culbong, M. (2005) “"We are not just participants - we are in charge": the NACCHO ear trial and the process for aboriginal community-controlled health research', Ethnicity \& Health, vol. 10, no. 2, pp. 91-111.

Devitt, J., Cass, A., Cunningham, J., Preece, C., Anderson, K. \& Snelling, P. (2008) 'Study protocol - improving access to kidney transplants (IMPAKT): a detailed account of a qualitative study investigating barriers to transplant for Australian indigenous people with end-stage kidney disease', BMC Health Services Research, vol. 8, p. 31.

Dudgeon, P., Kelly, K. \& Walker, R. (2010) 'Closing the gaps in and through indigenous health research: guidelines, processes and practices', Australian Aboriginal Studies, no. 2, pp. 81-91.

Eversole, R. \& Routh, R. (2005) 'Collaborative research as an anti-poverty tool: a research partnership between police and indigenous Australians', Development in Practice, vol. 15, no. 5, pp. 631-642.

Faulkhead, S. (2008) Narrative creation and Koorie Victoria, PhD thesis, Monash University, Melbourne.

Faulkhead, S. (2009) 'Connecting through records: narratives of Koorie Victoria', Archives and Manuscripts, vol. 37, no. 2, pp. 60-88.

Faulkhead, S., Russell, L., Singh, D. \& Mckemmish, S. (2007) 'Is community research possible within the western academic tradition?' in Researching with Communities: Grounded perspectives on Engaging Communities in Research, eds A. Williamson \& R. Desouza, Muddy Creek Press, Auckland, pp. 39-56.

Fitzgerald, T. (2005) 'Cross-cultural research principles \& partnerships', Management in Education, vol. 19, no. 1, pp. 17-20.

Foster, D., Williams, R., Campbell, D., Davis, V. \& Pepperill, L. (2006) "'Researching ourselves back to life": new ways of conducting aboriginal alcohol research', Drug and Alcohol Review, vol. 25, no. 3, pp. 213-217.

Greer, S. (2010) 'Heritage and empowerment: community-based Indigenous cultural heritage in northern Australia', International Journal of Heritage Studies, vol. 16, nos $1-2$, pp. 45-58.

Grieves, G. (2002) 'Keeping the culture alive, Koorie oral history', Koorie Heritage Trust Inc. Newsletter, no. 1, p. 3.

Guthrie, J., Dance, P., Cubillo, C., Mcdonald, D., Tongs, J., Brideson, T. \& Bammer, G. (2006) 'Working in partnership: Skills transfer in developing a cross-cultural research team', Journal of Community Psychology, vol. 34, no. 5, pp. 515-522.

Haswell-Elkins, M., Reilly, L., Fagan, R., Ypinazar, V., Hunter, E., Tsey, K., Gibson, V., Connolly, B., Laliberte, A., Wargent, R., Gibson, T., Saunders, V., Mccalman, J. \& Kavanagh, D. (2009) 'Listening, sharing understanding and facilitating consumer, family and community empowerment through a priority driven partnership in Far North Queensland', Australasian Psychiatry, vol. 17, pp. S54-S58. 
Israel, B. A., Schulz, A. J., Parker, E. A. \& Becker, A. B. (1998) 'Review of community-based research: assessing partnership approaches to improve public health', Annual Review of Public Health, vol. 19, pp. 173-202.

Laycock, A., Walker, D., Harrison, N. \& Brands, J. (2009) Supporting Indigenous Researchers: A Practical Guide for Supervisors, Cooperative Research Centre for Aboriginal Health, Darwin.

McBride, B. (2003) 'Aspects of community healing: experiences of the Sault Sainte Marie tribe of Chippewa Indians', American Indian Alaskan Native Mental Health Research, vol. 11, no. 1, pp. 67-83.

McCarthy, L., Ashton, P. \& Graham, H. (1997) Culture and Heritage: Oral History, Department of Environment, Canberra.

McCausland, R. \& Vivian, A. (2010) 'Why do some Aboriginal communities have lower crime rates than others? A pilot study', Australian \& New Zealand Journal of Criminology, vol. 43, no. 2, pp. 301-332.

Mercer, S., Green, L., Cargo, M., Potter, M., Daniel, M., Olds, S. \& Reed-Gross, E. (2008) 'Reliability tested guidelines for assessing participatory research projects', in Community-Based Participatory Research for Health: From Process to Outcomes, ed. M. M. N. Wallerstein, Jossey-Bass, San Francisco, pp. 407-418.

Merriam, S. B., Johnson-Bailey, J., Lee, M.-Y., Kee, Y., Ntseane, G. \& Muhamad, M. (2001) 'Power and positionality: negotiating insider/outsider status within and across cultures', International Journal of Lifelong Education, vol. 20, no. 5, pp. $405-416$.

Minkler, M. (2005) 'Community-based research partnerships: Challenges and opportunities', Journal of Urban Health, vol. 82, no. 2, pp. ii3-ii12.

Moreton-Robinson, A. (ed.) (2003) Tiddas Talkin' up to the White Woman: When Huggins et al. Took on Bell, Melbourne University Press, Melbourne.

Nagel, T., Robinson, G., Condon, J. \& Trauer, T. (2009) 'Approach to treatment of mental illness and substance dependence in remote Indigenous communities: results of a mixed methods study', Australian Journal of Rural Health, vol. 17, no. 4, pp. $174-182$.

National Health and Medical Research Council (2003a) Guidelines for ethical conduct in aboriginal and Torres Strait Islander health research, National Health and Medical Research Council, Canberra.

National Health and Medical Research Council (2003b) Values and ethics: guidelines for ethical conduct in aboriginal and Torres Strait Islander health research, Commonwealth of Australia, Canberra.

National Health and Medical Research Council (NHMRC) (2006) Keeping Research on Track: A Guide for Aboriginal and Torres Strait Islander Peoples About Health Research Ethics, National Health and Medical Research Council (NHMRC), [Online] Available at: http://www.nhmrc.gov.au/publications/synopses/e65syn.htm (20 May 2011).

Onemda Vichealth Koori Health Unit (2008) We Can Like Research. . .In Koori Hands, University of Melbourne, Melbourne. 
Oxford University (2012) Oxford Dictionaries, Oxford University Press, London, [Online] Available at: http:/ / oxforddictionaries.com/ (2 July 2012).

Paasse, G. \& Adams, K. (2011) 'Working together as a catalyst for change: the development of a Peer mentoring model for the prevention of chronic disease in Australian indigenous communities', Australian Journal of Primary Health, vol. 17, no. 3, pp. 214-219.

Pyper, W. (2005) 'Teamwork for a survey of sea country', ECOS, June-July, no. 125, pp. $17-19$.

Russell, L. (2005) 'Indigenous knowledge and archives: accessing hidden history and understandings', Australian Academic and Research Libraries, vol. 36, no. 2, pp. $169-180$.

Somerville, M. \& Perkins, T. (2003) 'Border work in the contact zone: thinking indigenous/non-indigenous collaboration spatially', Journal of Intercultural Studies, vol. 24, no. 3, pp. 253-266.

Tuhiwai Smith, L. (1999) Decolonizing Methodologies: Research and Indigenous Peoples, University of Otago Press, Dunedin.

Turner, K. \& Sanders, M. (2007) 'Family intervention in Indigenous communities: emergent issues in conducting outcome research', Australasian Psychiatry, vol. 15, pp. S39-S43.

VicHealth Koori Health Research and Community Development Unit (2000) We Don't Like Research: But in Koori Hands It Could Make a Difference: Community Report, The University of Melbourne, [Online] Available at: http://www. onemda.unimelb.edu.au/publications/publicationsReport_2000.html April 2012).

Watson, J., Hodson, K., Johnson, R. \& Kemp, K. (2002) 'The maternity experiences of Indigenous women admitted to an acute care setting', Australian Journal of Rural Health, vol. 10, no. 3, pp. 154-160.

Weston, R., Brooks, R., Gladman, J., Senior, K., Denley, L., Silove, D., Whyman, N., Kickett, M., Bryant, R. \& Files, J. (2009) 'Ethical research in partnership with an Indigenous community', Australasian Psychiatry, vol. 17, Supplemnt 1, pp. S51-S53.

Woolcock,M.(1998) 'Socialcapitalandeconomicdevelopment:towardsatheoreticalsynthesisandpolicyframework', Theory Society, vol.27, no. 2,pp. 151-208.

Karen Adams is an adjunct Associate Professor at Victoria University. Address: Moondani Balluk Indigenous Academic Unit, Victoria University, St Albans Campus VIC 8001, Australia. [email: karen.adams@vu.edu.au]

Shannon Faulkhead is a Senior Research Fellow at Monash University. Address: Monash Indigenous Centre, Monash University, VIC 3800, Australia. [email: shannon.faulkhead@monash.edu] 